$U$ shape or to the exponential configuration, but this is a range of pressures for which seating and other experimental errors are likely to be particularly important.

Exponential expressions like equation (2) of the discussion are most nearly applicable to soils that have small or no preconsolidation. With increasing preconsolidation the $U$ shape of the $D$ against $p$ or equivalent plots becomes more and more pronounced. The effect of preconsolidation on the shape of the plot is illustrated in the accompanying Fig. 4 for three different types of soil, i.e. (a) a remoulded organic clay with liquid limit of $82 \%$, plasticity index of $27 \%$, silt and clay sizes of $86 \%$, specific gravity of 2.83 and initial water content of $56 \%$; (b) a remoulded clayey sand with liquid limit of $31 \%$, plasticity index of $14 \%$, silt and clay sizes of $43 \%$, specific gravity of 2.75 and initial water content of $28 \%$; and (c) loose nonplastic sand with silt sizes of $5 \%, 48 \%$ passing through sieve No. $50,99 \%$ passing through sieve No. 10 , specific gravity of 2.64 , subangular, initial dry density of $1 \cdot 10 \mathrm{~g} / \mathrm{cm}^{3}$. From each of the three soil samples used, a series of five, as nearly identical as possible, oedometer specimens were prepared in a very loose condition; one of the specimens in each series was tested without preconsolidation but the remaining four were tested after first loading to $0.75 \mathrm{~kg} / \mathrm{cm}^{2}, 1.50 \mathrm{~kg} / \mathrm{cm}^{2}, 2.25 \mathrm{~kg} / \mathrm{cm}^{2}$ and $3.00 \mathrm{~kg} / \mathrm{cm}^{2}$ and then unloading (Fig. 4).

As exponential expressions (such as equation (2) of the discussion) are applicable to soils that have a small or no preconsolidation, they could be regarded as a particular form of the more general case of the $U$ shape curve, with the left half of the $U$ reduced to trivial size.

\title{
REFERENCE
}

Lambe, T. W. \& Whitman, R. V. (1969). Soil Mechanics. New York: John Wiley and Sons.

\section{A Note on Hvorslev's intake factors}

LOWTHER, G. (1978). Géotechnique 28, No. 4, 465-466

\section{E. G. Youngs, Physics Department, Rothamsted Experimental Station}

The Author draws attention to a difficulty encountered in the evaluation of permeability values from data obtained from tests on boreholes and piezometers. He notes that the formulae given by Hvorslev $(1949,1951)$ for the cases of a well point-filter are, in the limit of zero length of filter, different from those given for a flush bottom well, although they should be identical. This is not so surprising, since Hvorslev himself points out the approximate nature of some of the formulae he uses. This discussion outlines the physical basis of their derivation, and gives a comprehensive table of values of the shape factor which allows the determination of permeability from borehole tests for different lengths of filter and depth of well.

In the derivation of the intake formulae, which have the general form

$$
q=S k H D
$$

where $q$ is the discharge, $k$ the permeability of the soil, $H$ the head causing the flow, $D$ the diameter of the well point-filter, and $S$ a shape factor the value of which depends on the shape of the cavity and its depth relative to the impervious boundary, Hvorslev (1951) notes that sometimes assumptions concerning the shape of the well point-filter (or cavity below the end of the well) were made.

This was the case for the formulae obtained by Dachler (1936), quoted by Hvorslev, for the well point-filter or hole extended both in an infinite uniform soil and at an impervious 
boundary. Hvorslev notes particularly that Dachler emphasized that the formulae can provide only approximate results when they are applied to cylindrical intake or well points.

Dachler's formula for a well point-filter or cavity extended in an infinite uniform soil, in which case the shape factor $S$ in equation (1) has the form

$$
S=\frac{2 \pi L / D}{\ln \left\{L / D+\sqrt{\left.\left[1+(L / D)^{2}\right]\right\}}\right.}
$$

was derived on the basis of flow from a line source for which the equipotentials are ellipsoids. It would be expected to be better for a long cavity than for a short one since, when the length is zero, the value of the shape factor reduces to

$$
S=2 \pi
$$

that obtained theoretically for a spherical intake cavity. Thus, when compared with that obtained in the experiments of Harza (1935) and graphically by Taylor (1948) (Hvorslev, 1951) for the flush well bottom for which Hvorslev (1951) could find no analytical solution, a large discrepancy must be expected as the Author found.

Similarly, for the well point-filter or cavity at an impervious boundary, Dachler's formula for which $S$ takes the value

$$
S=\frac{2 \pi L / D}{\ln \left\{2 L / D+\sqrt{ }\left[1+(2 L / D)^{2}\right]\right\}} \quad . \quad . \quad . \quad . \quad . \quad . \quad .
$$

assumes the cylindrical cavity to be approximated by a semi-ellipsoid. Thus for a cavity of zero length

$$
S=\pi
$$

the theoretical value of the shape factor for a hemispherical cavity at an impervious boundary. This is to be compared with the value

$$
S=2
$$

obtained by potential theory for a well bottom flush with the impervious boundary. The discrepancy in this case is not quite so large as when the well point-filter is in an infinite uniform soil.

Hvorslev's tests were designed for confined aquifers. Piezometers and lined tubes are used also in the determination of permeability (hydraulic conductivity) in the groundwater zone near the soil surface for the purpose of land-drainage design (Kirkham, 1946; Luthin, 1957; van Schilfgaarde, 1974). In this situation, however, the upper boundary is a water table and the method requires an initial depression of the water level in the well, followed by an observation of the intake rate. Because of the different boundary condition at the upper surface of the flow region, the shape factors $S$ in the intake formula (equation (1)) in this situation are different from those in Hvorslev's intake formulae. For the tests in unconfined aquifers comprehensive tables of the shape factor, found by electric analogue, have been presented by Youngs (1968). Values calculated from potential theory using a computer by Boast (1969) agreed with the electric analogue values. While these shape factors are not generally applicable to the confined case, the boundary values for the confined and unconfined cases become the same for the well point or cavity at an infinite depth below the upper surface. Thus the shape factors given by Youngs (1968) for cavities at depth below the water table in an infinitely deep soil may be used also in the confined situation for a well point extended in infinite uniform soil. Youngs' table of shape factors shows that there is little change in the shape factor for a given 
cavity when the cavity is deeper than about six well diameters below the water table, especially for small cavity lengths, so that values at the greatest depth given of ten diameters may be taken as those for infinite soil in both the unconfined and confined situations. In Table 1 values given by equation (2) are compared with these electric analogue values. It is seen that agreement is poor for small ratios of $L / D$, the ratio of the length of cavity to diameter, but is within $10 \%$, accurate enough for practical purposes, for $L / D>0 \cdot 8$. Youngs' value of $2 \cdot 80$ for $L / D=0$ agrees well with that of 2.75 given by Hvorslev.

Table 1. Comparison of shape factors; $S_{\mathrm{Y}}$ after Youngs (1968), $S_{\mathrm{H}}$ from Dachler's (1936) formulae, quoted by Hvorslev (1951), $S_{\mathrm{A}}$ new analogue values

\begin{tabular}{|c|c|c|c|c|c|}
\hline \multirow[b]{2}{*}{$L / D$} & \multicolumn{2}{|c|}{$\begin{array}{l}\text { Well point in } \\
\text { infinite soil }\end{array}$} & \multicolumn{3}{|c|}{$\begin{array}{l}\text { Well point at } \\
\text { impervious boundary }\end{array}$} \\
\hline & $S_{\mathbf{Y}}$ & $S_{\mathbf{H}}$ & $S_{\mathrm{Y}}$ & $S_{\mathrm{H}}$ & $S_{\mathrm{A}}$ \\
\hline 0 & $2 \cdot 80$ & $6 \cdot 28$ & - & $3 \cdot 14$ & $2 \cdot 00^{1}$ \\
\hline 0.25 & $4 \cdot 35$ & $6 \cdot 34$ & $2 \cdot 40$ & $3 \cdot 26$ & 3.08 \\
\hline $0 \cdot 5$ & $5 \cdot 30$ & $6 \cdot 52$ & $3 \cdot 15$ & $3 \cdot 56$ & $3 \cdot 78$ \\
\hline 1.0 & 6.90 & $7 \cdot 13$ & 4.55 & $4 \cdot 35$ & 5.08 \\
\hline $2 \cdot 0$ & $9 \cdot 30$ & $8 \cdot 70$ & 6.80 & 6.00 & $7 \cdot 18$ \\
\hline 4.0 & 13.45 & $12 \cdot 00$ & $10 \cdot 70$ & 9.05 & 11.05 \\
\hline
\end{tabular}

${ }^{1}$ Theoretical value.

Table 2. Shape factors for well point-filters

\begin{tabular}{|c|c|c|c|c|c|c|c|}
\hline \multirow[b]{2}{*}{$L / D$} & \multicolumn{7}{|c|}{ Values of $S$ for $B / D$} \\
\hline & $\infty$ & $4 \cdot 0$ & $2 \cdot 0$ & $1 \cdot 0$ & 0.5 & 0.25 & 0 \\
\hline 0 & 2.80 & 2.75 & 2.65 & 2.50 & $2 \cdot 30^{1}$ & $2 \cdot 15^{1}$ & $2 \cdot 00$ \\
\hline 0.25 & $4 \cdot 35$ & $4 \cdot 30$ & $4 \cdot 15$ & 3.85 & $3 \cdot 50$ & $3 \cdot 30^{1}$ & 3.08 \\
\hline 0.5 & $5 \cdot 30$ & $5 \cdot 20$ & 5.00 & $4 \cdot 65$ & $4 \cdot 20$ & $4.00^{1}$ & $3 \cdot 78$ \\
\hline 1.0 & 6.90 & 6.75 & $6 \cdot 40$ & 5.95 & 5.45 & $5 \cdot 30^{1}$ & 5.08 \\
\hline $2 \cdot 0$ & $9 \cdot 30$ & $9 \cdot 00$ & 8.65 & $8 \cdot 15$ & 7.65 & $7 \cdot 40^{1}$ & $7 \cdot 18$ \\
\hline 4.0 & 13.45 & $13 \cdot 15$ & 12.75 & 12.00 & $11 \cdot 50$ & 11.20 & 11.05 \\
\hline
\end{tabular}

${ }^{1}$ Interpolated values.

For the case of the well point at an impervious boundary, values given by Youngs (1968) for cylindrical cavities in deep soils and which rest on a lower impermeable bed may be used as an approximation except for very small values of $L / D$. These values are also given in Table 1 , and are compared with those given by equation (4). Also shown for comparison are newly determined electric analogue values for cases of $L / D \neq 0$; for $L / D=0$, we can take the theoretical value of $S=2 \cdot 0$. In this case, values given for $S$ by equation (4) are within $12 \%$ of the analogue results for $L / D>0.25$. The values taken from Youngs (1968) are poor below $L / D=0 \cdot 5$, but are more accurate than equation (4) for $L / D>1 \cdot 0$, being only $3 \%$ different from the analogue results at $L / D=4 \cdot 0$.

This discussion indicates the degree of accuracy which may be expected in using the intake formulae given by Hvorslev (1951).

For greater accuracy, Table 2 has been drawn up to take into account the depth of the well point-filter below the impervious layer. The values in Table 2 have been taken from Youngs 
(1968), together with the analogue and theoretical results shown in Table 1. The shape factors at a depth $B$ below the impervious floor may be assumed to approximate to the values given in the tables of Youngs (1968) for cavities at depth and at heights $B$ above an impermeable floor, since even at the extreme values of $B=0$ for $L / D>0.5$, the shape factors obtained in this way are in error by only $20 \%$ even though the flow is through the cylindrical sides only because of the impermeable floor. Thus for values of $B / D$ not equal to zero or infinity, for which we have accurate values obtained by electric analogue, we may confidently use Youngs' analogue results using interpolated values for low values of $B / D$. Table 2 may thus be regarded as a comprehensive table of shape factors to be used in the intake formula (equation (1)).

\section{Author's Reply}

I would like to thank Mr Youngs for his most interesting contribution. The historical introduction is particularly elegant, laying emphasis as it does on the fact that the originators of the various theories were only too well aware of their approximate nature. His Table 2 should be a most valuable aid in obtaining more satisfactory permeability values. Though inspection of it shows how very rapidly the shape factor varies at small values of $L / D$. Consequently the depth of the borehole and lining tubes must be known with adequate precision if reasonable accuracy is to be obtained.

\section{REFERENCES}

Boast, C. W. (1969). Potential flow to a piezometer or a well partially penetrating a porous medium. MS thesis, Iowa State University.

Dachler, R. (1936). Grundwasserströmung. Vienna: J. Springer.

Harza, L. F. (1935). Uplift and seepage under dams. Trans. Am. Soc. Civ. Engrs 100, 1352-1385.

Hvorslev, M. J. (1949). Time lag in the observation of groundwater levels and pressures. U.S. Army Experiment Station, Vicksburg, Mississippi.

Hvorslev, M. J. (1951). Time lag and soil permeability in groundwater observations. Bulletin No. 36. Waterways Experiment Station, Vicksburg, Mississippi.

Kirkham, D. (1946). Proposed method for field measurement of permeability of soil below the water table. Soil Sci. Soc. Am. Proc. 10, 58-68.

Luthin, J. N. (ed.) (1957). Drainage of agricultural lands. American Society of Agronomy.

Taylor, D. W. (1948). Fundamentals of soil mechanics. New York: John Wiley \& Sons.

van Schilfgaarde, J. (ed.) (1974). Drainage for agriculture. American Society of Agronomy.

Youngs, E. G. (1968). Shape factors for Kirkham's piezometer method for determining the hydraulic conductivity of soil in situ for soils overlying an impermeable floor or infinitely permeable stratum. Soil Sci.106, 235-337.

\section{A discrete numerical model for granular assemblies}

CUNDALl, P. A. \& STRACK, O. D. L. (1979). Géotechnique 29, No. 1, 47-65.

\section{B. C. Burman, Coffey \& Partners Pty Ltd}

The Authors have produced an interesting paper on the application of numerical modelling of discontinua to the investigation of constitutive relationships for granular materials. The Writer (Burman, 1972) was involved in similar work between 1969 and 1971, the results of which are belatedly published (Trollope \& Burman, 1980).

The senior Author and the Writer have independently developed similar but different approaches to the numerical analysis of discontinua with a view to mathematically modelling the behaviour of jointed masses in problems of rock mechanics. While Cundall chose to 